\title{
Commensal bacteria promote type I interferon signaling to maintain immune tolerance
}

Adriana Vasquez Ayala ${ }^{1, \#}$, Kazuhiko Matsuo ${ }^{1,2, \#, ~ C h i a-Y u n ~} \mathrm{Hsu}^{1}$, Marvic Carrillo Terrazas ${ }^{1}$, Hiutung Chu ${ }^{1,3,4^{*}}$

${ }^{1}$ Department of Pathology, University of California San Diego, La Jolla, CA, United States

${ }^{2}$ Division of Chemotherapy, Kindai University Faculty of Pharmacy, Higashi-osaka, Osaka, Japan

${ }^{3}$ Chiba University-UC San Diego Center for Mucosal Immunology, Allergy and Vaccines (cMAV), University of California, San Diego, La Jolla, CA, United States

${ }^{4}$ Humans and the Microbiome Program, Canadian Institute for Advanced Research, Toronto, ON M5G 1M1, Canada

\#These authors contributed equally

*corresponding author hiuchu@ucsd.edu 


\section{SUMMARY}

Type I interferons (IFN) play essential roles in numerous physiological processes, acting as central coordinators in the host response against pathogens. Upon sensing of microbial ligands, host cells rapidly activate the type I IFN response to prime innate and adaptive immune responses. Recent studies suggest tonic IFN are maintained by commensal microbes and critical in mounting an effective immune response to viral pathogens. Further, emerging developments have extended an immunoregulatory role of type I IFN in the maintenance of immune homeostasis. Yet whether immunomodulatory bacteria from the gut microbiota operate through IFN signaling to promote immune tolerance remains largely unanswered. Here we show that commensal microbes are necessary to maintain type I IFN responses in intestinal tissues. Specifically, Bacteroides fragilis induced type I IFN response in dendritic cells (DCs) and this pathway is necessary for the induction of IL-10-producing Foxp3 ${ }^{+}$ regulatory T cells (Tregs). In addition, we show upregulation of type I IFN related genes in Tregs from mesenteric lymph nodes and colonic lamina propria of mice colonized with $B$. fragilis. Our findings demonstrate type I interferon signaling plays an important role in microbiota-mediated immune tolerance in the gut. 


\section{INTRODUCTION}

Type I interferons (IFN) are involved in many essential immune functions, influencing both innate and adaptive immune effector responses (1-3). Type I IFNs, namely IFNa and IFN $\beta$, are produced upon sensing a variety of microbial products resulting in the expression of interferon-stimulated genes (ISG). While several hundred ISGs with various known functions have been identified, IFN has primarily been studied in its role in orchestrating antiviral immunity $(4,5)$. The role of IFN signaling in response to bacterial products, and how this may influence immune homeostasis in particular, is poorly understood. Recent work suggests that commensal microbes are involved in maintaining tonic type I IFN necessary to mount an effective antiviral immune response (6-9). Indeed, apart from the induction of anti-viral ISGs, type I IFN can promote dendritic cell (DC) activation and maturation to enhance antigen presentation to prime adaptive immunity. Further, tonic type I IFN expression, driven by various microbial signals, is essential for effective $T$ cell responses (10-14). These studies underscore the importance to further understand the role of microbial-induced IFN and its impact on host immunity.

Of particular interest is the divergent effect of IFN on immune responses that may depend on the context of microbial exposure. For instance, during intracellular infections, microbial sensing by cytosolic pathogen recognition receptors (PRRs) can lead to amplification of type I IFN signaling and subsequent induction of STAT1, an ISG product responsible for downstream inflammatory cytokine production (3). Type I IFN responses to microbial pathogens can thus generate a robust antimicrobial and pro-inflammatory response via activation of ISGs. On the other hand, detection of microbial products during homeostatic conditions leads to basal type I IFN signaling which may then promote anti-inflammatory responses (15). This tonic IFN expression is critical in priming immune cells to rapidly mobilize (6-8), but it also suppresses proliferation of pathogenic $T$ cell responses and the production of pro-inflammatory cytokines. Recent studies also suggest that type I IFN may influence regulatory $T$ cell (Treg) function. Notably, signaling via interferon- $\alpha / \beta$ receptor 1 (IFNAR1) is required for Treg expansion and function in tumor microenvironment $(16,17)$. Furthermore, Tregs from IFNAR1-deficient mice do not suppress the activation of pathogenic T cells in the colitis model, compared to wildtype controls (18). In contrast, Stat $1^{-/}$Tregs demonstrated enhanced suppression of T cells and in preventing the development of graft versus host disease (19). Thus, while it has been clear that type I IFN signaling does play a role in Treg function, the mechanisms that regulate its contribution have remained elusive. These findings implicate the potential for IFN in regulating Treg function and maintaining mucosal homeostasis.

Genome wide association studies have identified genes in the IFN pathway linked to inflammatory bowel disease (IBD) susceptibility. IFNAR1 has been suggested to be an IBD risk allele, and single nucleotide polymorphisms (SNPs) in JAK2, TYK2, STAT1 and STAT3 can have major consequences in the JAK/STAT pathway, including dysregulation of cytokine production (20). Clinical and experimental evidence suggest gut bacteria play a pivotal role in governing immune responses during IBD. For instance, the bacterial metabolite, butyrate, has been demonstrated to suppress the expression of type I IFN genes in DCs by preventing phosphorylation of TBK1 and IRF3, suggesting one mechanism by which the microbiota can attenuate type I IFN function (21). Moreover, 
glycolipids from commensal Bacteroides have been reported to promote anti-viral function via IFN $\beta$ expression in DCs (22). Lastly, while most reports show the intersection of microbiota and type I IFN signaling in DCs, such effects have been reported in other cell types, for example lung stroma cells (9). Together, these reports suggest that the microbiota plays a role in regulating type I IFN responses and their downstream effects on DC and T cell function.

Here, we aimed to understand whether tonic IFN induced by commensal bacteria are required for tolerogenic immune responses. Previous work from our group and others demonstrated that Bacteroides fragilis prime DCs to promote Foxp3+ Treg responses to control intestinal inflammation. Given the role of gut microbes in maintaining tonic IFN expression, we hypothesized that commensal bacteria may signal via type I IFN pathways to direct intestinal immune tolerance. In the present study, we found that germ-free (GF) mice are indeed deficient in IFN responses and colonization with a single commensal bacterium, $B$. fragilis, partially restores tonic type I IFN expression comparable to specific pathogen free (SPF) mice. Notably, $B$. fragilis induced IFN $\beta$ and type I IFN signaling in dendritic cells (DCs) are required for commensal induced Foxp3+ Treg responses. Finally, while investigating $B$. fragilis-mediated gene signatures in Treg cells, we discovered an enrichment of IFN related genes among intestinal Foxp3+ Treg cells. Our findings demonstrate that type I IFN signaling promotes intestinal homeostasis via commensal microbiota. 


\section{RESULTS}

\section{Commensal bacteria maintain intestinal type I IFN responses}

Emerging evidence suggest commensal bacteria are important regulators of tonic type I IFN signaling $(23,24)$ and are required to mount an effective immune response to pathogens (6). Given the pleiotropic effects of type I IFN, we examined the association between the microbiota and type I IFN signaling in the gut during steadystate. Expression of IFN-related genes was assessed in colon tissue of germ-free (GF) and specific pathogenfree (SPF) mice. The presence of a commensal microbial community was required for the induction of Ifnb and $M x 1$ expression in the colon (Figure 1A). Mono-colonization of GF mice with the commensal bacterium, $B$. fragilis, was sufficient to partially restore IFN-related gene expression in the gut (Figure $1 \mathrm{~A}$ ). We next investigated the contribution of the microbiota in priming local intestinal type I IFN responses upon microbial stimulation. Colon explants from GF and SPF mice were cultured for 24 hours with polyinosinic-polycytidylic acid (poly I:C), a Toll-like receptor (TLR) agonist and potent inducer of IFN $\beta$. While poly I:C induced a significant increase in IFN $\beta$ secretion in SPF colon explants, GF tissues remained unresponsive to poly I:C (Figure 1B). Since type I IFN are constitutively expressed in the gut by CD11C+ DCs $(22,25,26)$, we next investigated whether microbial signals influenced autocrine IFNAR signaling in DCs. Colonic lamina propria cells were isolated from SPF and GF mice and restimulated with IFN $\beta$ ex vivo. Gut CD11C+ DCs from SPF mice responded to IFN $\beta$ stimulation via increased phosphorylation of signal transducer and activator of transcription 1 (STAT1), as measured by flow cytometry (Figure 1C). However, intestinal CD11C+ cells from GF mice did not show increased levels of pSTAT1 following IFN $\beta$ stimulation, consistent with defects in autocrine signaling. These data support the notion that the gut microbiota is important in maintaining type I IFN responses in mucosal tissues.

\section{B. fragilis induces IFN $\beta$ expression in dendritic cells to coordinate Treg response}

In order to understand how the microbiota maintain tonic type I IFN responses, we utilized $B$. fragilis as a model commensal bacteria since mono-colonization with $B$. fragilis was sufficient to restore intestinal IFN $\beta$ responses (Figure 1A). Previous work revealed DCs serve as orchestrators of $B$. fragilis-mediated immune tolerance (2729). For instance, both TLR2 and NOD2 signaling are required for DCs to recognize $B$. fragilis in order to promote Treg responses $(27,29)$, indicating both cell surface and cytosolic sensing of commensal bacteria are important in coordinating a tolerogenic DC response. Further, DCs are major producers of type I IFN (30). Therefore, we hypothesized that $B$. fragilis may engage the IFN pathway in DCs, as the microbiota has been linked to type I IFN in directing DC function (26). To evaluate if $B$. fragilis mediated immune tolerance is in part achieved via IFN, we measured IFN related gene expression in DCs treated with $B$. fragilis in vitro. Bone marrow derived dendritic cells (BMDCs) treated with $B$. fragilis significantly induced expression and secretion of IFN $\beta$, but not IFN $\alpha$ or IFNy (Figures $2 A$ and $2 B$ ). To test if $B$. fragilis promotes autocrine IFN signaling in DCs to maintain IFN $\beta$ expression, pSTAT1 levels were measured by flow cytometry. Expression of pSTAT1 in BMDCs significantly increased as a result of $B$. fragilis treatment (Figure $2 C$ ). 
$B$. fragilis is known to prime DCs to direct Treg responses via DCs $(27,29)$. We evaluated the necessity of type I IFN signaling for $B$. fragilis-induced immune tolerance using DCs deficient in IFNAR. Wildtype (WT) or Ifnar BMDCs were pulsed with $B$. fragilis and co-cultured with CD4+ T cells from Foxp3 ${ }^{\text {hCD2}} / \mathrm{IL}-10^{\text {Venus }}$ reporter mice. Treatment of WT DCs with $B$. fragilis promoted induction of IL-10-producing Tregs (Figure 3A). However, $B$. fragilis treated Ifnar1/- BMDCs resulted in a significant reduction in IL-10+ Treg populations. This trend was also observed in CD4+ T cells cultured with untreated Ifnar1 ${ }^{--}$BMDCs (Figure 3A). B. fragilis-treated Ifnar1 ${ }^{-/}$DCs also revealed decreased IL-10 secretion as detected by ELISA, relative to WT DCs (Figure 3B). Thus, type I IFN signaling in DCs is critical for commensal bacteria to direct Treg responses, even when IFN signaling is intact in T cells. Indeed, while B. fragilis significantly induced type I IFN related genes in WT DCs (e.g., Ifnb, Mx1, Oas1, and $M \times 2$ ), Ifnar1-DCs remained unresponsive (Figure 3C). Interestingly, this induction appears to be selective, as expression of certain IFN-response genes (e.g., Irf3, Irf9) are either unaffected or inhibited by $B$. fragilis. In addition, expression of IFNa also appears to be unaffected by $B$. fragilis in WT DCs (Figure 2A), suggesting perhaps some specificity in the induction of type I IFN gene expression downstream of PRRs.

\section{Bacterial colonization promotes IFN gene signature in gut Tregs}

Given the requirement of type I IFN signaling for $B$. fragilis induced Treg responses in vitro, we asked whether the gene signature of intestinal Tregs are associated with tonic IFN upon bacterial colonization. To examine this link, we performed single cell RNA sequencing of gut Tregs from GF and $B$. fragilis mono-colonized mice during steady-state (Figure 4A). To delineate the relationships between Treg populations, we applied tSNE to mesenteric lymph nodes (MLN) and colonic lamina propria (CLP) datasets individually (Figure 4B). Tregs from MLN of GF and $B$. fragilis mono-colonized mice partitioned into two distinct areas, a pattern similarly observed in Tregs from cLP (Figure 4B). Notably, Tregs from colon and MLN of $B$. fragilis mono-colonized mice exhibited a significant upregulation in IFN related-genes, such as Mx1, Ifit1, Stat1, and members of the Oas gene family (Figure 4C). This data supports that type I IFN activity is a prominent pathway induced in Tregs by commensal bacteria. 


\section{DISCUSSION}

Commensal bacteria interact with various PRRs expressed by DCs to influence activation of the adaptive immune response. One these responses is the induction of Tregs as a result of signaling from commensalprimed DCs. It is also known that intestinal DCs produce and maintain type I IFN in response to microbial sensing, as reported in previous studies $(22,25,26)$. Our data uncovers the requirement of type I IFN signaling in DCs by commensal bacteria for the induction of Tregs. Specifically, we identified IFN $\beta$ produced by DCsstimulated by $B$. fragilis to be a critical cytokine in inducing Tregs and their function. These data are in support of a recent study that indicated $B$. fragilis promotes anti-viral responses through induction of ISG expression and type I IFN (22)

The impact of type I IFN on Treg cells, however, remains controversial. Indeed, type I IFN has been reported to be critical for the maintenance of Foxp3 expression and the suppressive activity of Tregs, including the induction of IL-10 $(16,18,25)$. Conversely, other reports indicate that type I IFN inhibits Treg cell proliferation and activation of Foxp3 ${ }^{+}$Tregs $(31,32)$. There are also paradoxical roles of STAT1, the main transducer of IFNs, in Treg homeostasis. STAT1-deficiency has been reported to promote expansion of Tregs (19), yet also resulted in impaired IL-10 production in Treg cells to restrain Th17 inflammation. Another potential conflicting observation is the role of ATG16L1 (an IBD-risk allele) in controlling type I IFN. Increased ISG expression and type I IFN signaling were reported in Atg16L $1^{H M}$ mice, and this enhanced response was dependent on the microbiota (33). These findings suggest the autophagy pathway is important in controlling spontaneous activation of type I IFN responses by gut microbes. In contrast, our previous work demonstrated that $B$. fragilis requires ATG16L1 in DCs to direct downstream Treg responses during colitis (29), and we now report that $B$. fragilis-mediated tolerance operates, in part, via type I IFN. This discrepancy likely reflects the duality of type I IFN responses, capable of both immunostimulatory and suppressive regulatory functions. Moreover, the responsiveness to type I IFN is context dependent. Neutralization of IFN $\beta$ resulted in decreased IL-10 production by intestinal CD4 T cells in healthy controls, yet increased pro-inflammatory cytokine secretion in T cells from IBD patients (34). Indeed, the locus containing IFNAR, the receptor of type I IFNs, was also identified as a susceptibility region for IBD (20). While type I IFN therapies have been largely unsuccessful in IBD $(35,36)$, the contribution of the microbiota-regulated IFN may play a key role in promoting mucosal health.

Our study examines the contribution of commensal bacteria in shaping the regulation of homeostatic type I IFN response and its impact on immune tolerance. We argue that defects in microbiota-induced IFN signaling in DCs inhibit its intrinsic ability to induce Tregs in the intestine. Consistent with existing literature, we show that IFN $\beta$ is produced by DCs in response to commensal bacteria, which was found to confer protection against viral infection (22). Although we believe DCs are a major contributor for type I IFN mediated induction, it is possible commensal microbes regulate IFN pathways in other antigen presenting cells. Additionally, it is unknown which microbial sensing pathways are relied upon for this type I IFN-related communication between DCs and Tregs. Further 
bioRxiv preprint doi: https://doi.org/10.1101/2021.10.21.464743; this version posted October 21, 2021. The copyright holder for this preprint (which was not certified by peer review) is the author/funder, who has granted bioRxiv a license to display the preprint in perpetuity. It is made available under aCC-BY-NC-ND 4.0 International license.

study of the requirement type I IFN for intestinal homeostasis could be critical for the development of therapeutic treatments for IBD and other immune-mediated diseases. 


\section{Acknowledgements}

We thank members of the Chu lab for technical support and helpful discussions. We thank the Flow Cytometry Core Facility at the La Jolla Institute and Cheryl Kim for their expertise and instrument support. This work was supported by R00 DK110534 and P30 DK120515 from the National Institute of Diabetes, Digestive and Kidney Diseases (NIDDK) and the Chiba University-UC San Diego Center for Mucosal Immunology, Allergy and Vaccines (cMAV) to H.C. Additional support was provided to H.C. by CIFAR Humans and the Microbiome Program and The Hartwell Foundation. M.C.T was supported by T32 DK007202 (NIDDK), the National Academies of Sciences, Engineering and Medicine through the Predoctoral Fellowship of the Ford Foundation, and the Howard Hughes Medical Institute (HHMI) Graduate Fellowships grant (GT15123).

\section{Author Contributions}

H.C. conceived the project and designed the experiments. A.V.A., K.M., C.Y.H., M.C.T., and H.C. performed the experiments. K.Z. performed computational analyses and A.V.A., K.M., C.Y.H., M.C.T., and H.C. analyzed the data. H.C. supervised the project and wrote the manuscript, with contribution from all authors.

\section{Declaration of interests}

The authors declare no competing interests. 


\section{MATERIALS \& METHODS}

\section{Mice}

Germ-free C57CL/6J were bred and housed in flexible film isolators. Foxp3 ${ }^{\mathrm{hCD} 2} / \mathrm{IL}-10^{\text {Venus }}$ were obtained from K. Honda (37) and re-derived germ-free. For monocolonization experiments, 4- to 6-week-old male and female germ-free mice were transferred to autoclaved positive-pressured iso-cages (Allentown), fed ad libitum with autoclaved mouse chow (Lab Diet 5010) with autoclaved drinking water supplemented with $100 \mu \mathrm{g} / \mathrm{ml}$ of gentamicin (VetOne). Specific pathogen-free C57CL/6J and Ifnar1/-- (Stock No. 028288) were purchased from The Jackson Laboratory.

All procedures were performed in accordance with the guidelines and approved protocols from the IACUC of UC San Diego.

\section{Gnotobiotic monocolonization experiments}

4- to 6-week-old male and female germ-free mice were orally gavaged with a single dose of Bacteroides fragilis ( $10^{8}$ CFU resuspended in sterile PBS). Monocolonized mice were housed in autoclaved cages with autoclaved chow and drinking water supplemented with $100 \mu \mathrm{g} / \mathrm{ml}$ of gentamicin. B. fragilis strains used are naturally resistant to gentamicin. Fresh fecal samples were collected weekly during cage changing for plating on selective media and germ-free or $B$. fragilis colonization status were confirmed by PCR.

\section{RNA isolation and quantitative real-time RT-PCR}

Cells were harvested, washed, and immediately lysed in RLT buffer for RNA isolation using the RNeasy Mini Kit, according to the manufacturer's protocol (Qiagen). Tissue was harvested and placed in RNAlater (Invitrogen), homogenized, and lysed according to the manufacturer's protocol (Qiagen). One ug of RNA was reversed transcribed using SuperScript IV Reverse Transcriptase according to the manufacturer's protocol (Thermo) and diluted to $10 \mathrm{ug} / \mathrm{ul}$ based on the input concentration of total RNA. Gene specific primers were synthesized by Integrated DNA Technologies and sequences are provided in Table 1. Real-time PCR was performed on cDNA using the QuantStudio (Thermo).

\section{Colon explant cultures}

$1 \mathrm{~cm}$ of colon was cut from tissue cleaned with 1X PBS. The tissue was placed in $500 \mu \mathrm{l}$ of complete RPMI 1640 (10\% fetal bovine serum, $50 \mathrm{U} / \mathrm{ml}$ penicillin, $50 \mu \mathrm{g} / \mathrm{ml}$ streptomycin, $2 \mathrm{mM}$ L-glutamine, $1 \mathrm{mM}$ sodium pyruvate, 1 mM HEPES, non-essential amino acids, and beta-mercaptoethanol; Gibco) and cultured for 18-24 hours with or without stimulation with polyinosinic-polycytidylic acid (poly I:C; Sigma) in $37 \stackrel{\circ}{\mathrm{C}}$ and $5 \% \mathrm{CO}_{2}$. Supernatant were then collected and stored in $-20^{\circ} \mathrm{C}$ and used for quantification of cytokine secretion by ELISA. 


\section{In vitro DC:T cell co-culture}

Co-culture of bone marrow-derived dendritic cells (BMDCs) and CD4+ T cells were performed previously described (29). Briefly, BMDCs were generated from bone marrow progenitor cells isolated from femurs of WT or IFNAR1-deficient mice in the presence of $20 \mathrm{ng} / \mathrm{ml} \mathrm{GM-CSF}$ (Miltenyi) in complete RPMI 1640 (10\% fetal bovine serum, $50 \mathrm{U} / \mathrm{ml}$ penicillin, $50 \mu \mathrm{g} / \mathrm{ml}$ streptomycin, $2 \mathrm{mM}$ L-glutamine, $1 \mathrm{mM}$ sodium pyruvate, $1 \mathrm{mM}$ HEPES, non-essential amino acids, and beta-mercaptoethanol). BMDCs were pulsed with PBS, Bacteroides fragilis at $\mathrm{MOI}$ of 1 or 5 for 18-24 hours. BMDCs were washed and co-cultured with splenic CD4+ T cells at a ratio of 1:10 (DC:CD4+ T cells) in the presence of anti-mouse CD3 (eBiosciences), mouse IL-2 (Peprotech), and human TGF-beta (Peprotech). After 3 days of co-culture, supernatants were collected and stored at $-20 \stackrel{\circ}{ } \mathrm{C}$ for ELISAs and cells stained with specific antibodies and viability dye for analysis by flow cytometry.

\section{Flow cytometry and ELISA}

Cells were stained for $30 \mathrm{~min}$ at $4 \stackrel{\circ}{\circ}$ with either LIVE/DEAD fixable violet or aqua dead stain Kit (Life Technologies), with empirically titrated concentrations of the following antibodies: PE-Cy7-conjugated antimouse CD4 (clone: RM4-5), PE-conjugated anti-human CD2 (clone: RPA-2.10), APC-conjugated anti-mouse CD25 (clone: PC61.5). For intracellular staining, cells were fixed and permeabilized using the Transcription Factor Phospho Buffer Set (BD Pharmigen) according to manufacturer's protocol. Intracellular staining was performed with the following antibodies: AlexaFluor647-conjugated anti-mouse pSTAT1 (clone: Ser727), and/or FITC-conjugated anti-mouse Foxp3 (clone: FJK-16s) for 1 hour. All antibodies were purchased from Thermo Scientific/eBiosciences, BD, and Biolegend. Cell acquisition was performed on FACSCelesta (BD), and data was analyzed using FlowJo software suite (TreeStar). For ELISAs, cell supernatant from in vitro DC-T cell co-cultures were collected and IL-10 was measured using a commercially available kit (Thermo Scientific/eBiosciences).

\section{Isolation of cells from tissues}

Mesenteric lymph nodes (MLN) were processed by mashing tissues through $100 \mu \mathrm{m}$ cell strainer (BD Falcon) to generate single cell suspensions. Colon tissues were cut open longitudinally and luminal contents were flushed with cold PBS. Colon tissues were cut into $1 \mathrm{~cm}$ pieces and incubated in $10 \mathrm{mM}$ DTT with gentle shaking at 37 $\stackrel{\circ}{ } \mathrm{C}$ for $20 \mathrm{~min}$, followed by incubation in $20 \mathrm{mM}$ EDTA for $20 \mathrm{~min}$. Supernatant were removed and the remaining tissues were incubated in $1 \mathrm{mg} / \mathrm{ml}$ Collagenase $D$ and $0.5 \mathrm{mg} / \mathrm{ml}$ DNase I. Colonic lamina propria cells were filtered through a $70 \mu \mathrm{m}$ cell strainer and separated by $40 \%: 80 \%$ Percoll density gradient. Enrichment of CD4 ${ }^{+}$ and Foxp $3^{\text {hCD2+ }}$ cells were performed using MACS beads (Miltenyi).

\section{Single cell RNA sequencing}

Mesenteric lymph nodes (MLN) and colonic lamina propria (cLP) single-cell suspensions were loaded onto a Chromium Single Cell Chip (10x Genomics) according to manufacturer's protocol. mRNA was barcoded during cDNA synthesis and pooled for Illumina sequencing. Libraries were sequenced with an 8 base index read on a Novaseq 6000. FASTQ files were demultiplexed and aligned using Cell Ranger. 
bioRxiv preprint doi: https://doi.org/10.1101/2021.10.21.464743; this version posted October 21, 2021. The copyright holder for this preprint (which was not certified by peer review) is the author/funder, who has granted bioRxiv a license to display the preprint in perpetuity. It is made available under aCC-BY-NC-ND 4.0 International license.

\section{Statistical analysis}

Student's t-test was used for pairwise comparisons. One-way and two-way ANOVA with Post-hoc Tukey test were used for comparisons among one or more groups, respectively, using the GraphPad PRISM software. 
bioRxiv preprint doi: https://doi.org/10.1101/2021.10.21.464743; this version posted October 21,2021 . The copyright holder for this preprint (which was not certified by peer review) is the author/funder, who has granted bioRxiv a license to display the preprint in perpetuity. It is made available under aCC-BY-NC-ND 4.0 International license.

\section{REFERENCES}

1. Trinchieri G. Type I interferon: friend or foe? Journal of Experimental Medicine. 2010 Sep 13;207(10):2053-63.

2. Ivashkiv LB, Donlin LT. Regulation of type I interferon responses. Nat Rev Immunol. 2014 Jan;14(1):3649.

3. McNab F, Mayer-Barber K, Sher A, Wack A, O'Garra A. Type I interferons in infectious disease. Nat Rev Immunol. 2015 Feb;15(2):87-103.

4. Schoggins JW, Wilson SJ, Panis M, Murphy MY, Jones CT, Bieniasz P, et al. A diverse range of gene products are effectors of the type I interferon antiviral response. Nature. 2011 Apr;472(7344):481-5.

5. Schoggins JW. Interferon-Stimulated Genes: What Do They All Do? Annual Review of Virology. 2019;6(1):567-84.

6. Abt MC, Osborne LC, Monticelli LA, Doering TA, Alenghat T, Sonnenberg GF, et al. Commensal Bacteria Calibrate the Activation Threshold of Innate Antiviral Immunity. Immunity. 2012 Jul 27;37(1):158-70.

7. Ganal SC, Sanos SL, Kallfass C, Oberle K, Johner C, Kirschning C, et al. Priming of Natural Killer Cells by Nonmucosal Mononuclear Phagocytes Requires Instructive Signals from Commensal Microbiota. Immunity. 2012 Jul 27;37(1):171-86.

8. Yang X-L, Wang G, Xie J-Y, Li H, Chen S-X, Liu W, et al. The Intestinal Microbiome Primes Host Innate Immunity against Enteric Virus Systemic Infection through Type I Interferon. mBio. 12(3):e00366-21.

9. Bradley KC, Finsterbusch K, Schnepf D, Crotta S, Llorian M, Davidson S, et al. Microbiota-Driven Tonic Interferon Signals in Lung Stromal Cells Protect from Influenza Virus Infection. Cell Reports. 2019 Jul 2;28(1):245-256.e4.

10. Aman MJ, Tretter T, Eisenbeis N, Bug G, Decker T, Aulitzky WE, et al. Interferon- $\alpha$ Stimulates Production of Interleukin-10 in Activated CD4+ T Cells and Monocytes. Blood. 1996 Jun 1;87(11):4731-6.

11. Levings MK, Sangregorio R, Galbiati F, Squadrone S, Malefyt R de W, Roncarolo M-G. IFN- $\alpha$ and IL-10 Induce the Differentiation of Human Type 1 T Regulatory Cells. The Journal of Immunology. 2001 May 1;166(9):5530-9.

12. Bilsborough J, George TC, Norment A, Viney JL. Mucosal CD8a+ DC, with a plasmacytoid phenotype, induce differentiation and support function of T cells with regulatory properties. Immunology. 2003 Apr;108(4):481-92.

13. Wilson EB, Yamada DH, Elsaesser H, Herskovitz J, Deng J, Cheng G, et al. Blockade of chronic type I interferon signaling to control persistent LCMV infection. Science. 2013 Apr 12;340(6129):202-7.

14. Teijaro JR, Ng C, Lee AM, Sullivan BM, Sheehan KCF, Welch M, et al. Persistent LCMV infection is controlled by blockade of type I interferon signaling. Science. 2013 Apr 12;340(6129):207-11.

15. Lee AJ, Ashkar AA. The Dual Nature of Type I and Type II Interferons. Frontiers in Immunology. 2018;9:2061.

16. Stewart CA, Metheny H, lida N, Smith L, Hanson M, Steinhagen F, et al. Interferon-dependent IL-10 production by Tregs limits tumor Th17 inflammation. J Clin Invest. 2013 Nov 1;123(11):4859-74.

17. Kawano Y, Zavidij O, Park J, Moschetta M, Kokubun K, Mouhieddine TH, et al. Blocking IFNAR1 inhibits multiple myeloma-driven Treg expansion and immunosuppression. J Clin Invest. 2018 Jun 1;128(6):2487-99. 
bioRxiv preprint doi: https://doi.org/10.1101/2021.10.21.464743; this version posted October 21,2021 . The copyright holder for this preprint (which was not certified by peer review) is the author/funder, who has granted bioRxiv a license to display the preprint in perpetuity. It is made available under aCC-BY-NC-ND 4.0 International license.

18. Lee SE, Li X, Kim JCK, Lee J, González-Navajas JM, Hong SH, et al. Type I Interferons Maintain Foxp3 Expression and T-Regulatory Cell Functions Under Inflammatory Conditions in Mice. Gastroenterology. 2012 Jul 1;143(1):145-54.

19. Ma H, Lu C, Ziegler J, Liu A, Sepulveda A, Okada H, et al. Absence of Stat1 in donor CD4+ ${ }^{+}$cells promotes the expansion of Tregs and reduces graft-versus-host disease in mice. J Clin Invest. $2011 \mathrm{Jul}$ $1 ; 121(7): 2554-69$.

20. Jostins L, Ripke S, Weersma RK, Duerr RH, McGovern DP, Hui KY, et al. Host-microbe interactions have shaped the genetic architecture of inflammatory bowel disease. Nature. 2012 Nov;491(7422):119-24.

21. Yang K, Hou Y, Zhang Y, Liang H, Sharma A, Zheng W, et al. Suppression of local type I interferon by gut microbiota-derived butyrate impairs antitumor effects of ionizing radiation. J Exp Med. 2021 Mar $1 ; 218(3): e 20201915$.

22. Stefan KL, Kim MV, Iwasaki A, Kasper DL. Commensal Microbiota Modulation of Natural Resistance to Virus Infection. Cell. 2020 Nov 25;183(5):1312-1324.e10.

23. Sonnenburg JL, Chen CTL, Gordon JI. Genomic and Metabolic Studies of the Impact of Probiotics on a Model Gut Symbiont and Host. PLOS Biology. 2006 Nov 28;4(12):e413.

24. Yamamoto M, Yamaguchi R, Munakata K, Takashima K, Nishiyama M, Hioki K, et al. A microarray analysis of gnotobiotic mice indicating that microbial exposure during the neonatal period plays an essential role in immune system development. BMC Genomics. 2012 Jul 23;13(1):335.

25. Kole A, He J, Rivollier A, Silveira DD, Kitamura K, Maloy KJ, et al. Type I IFNs Regulate Effector and Regulatory T Cell Accumulation and Anti-Inflammatory Cytokine Production during T Cell-Mediated Colitis. The Journal of Immunology. 2013 Sep 1;191(5):2771-9.

26. Schaupp L, Muth S, Rogell L, Kofoed-Branzk M, Melchior F, Lienenklaus S, et al. Microbiota-Induced Type I Interferons Instruct a Poised Basal State of Dendritic Cells. Cell. 2020 May 28;181(5):10801096.e19.

27. Shen Y, Torchia MLG, Lawson GW, Karp CL, Ashwell JD, Mazmanian SK. Outer Membrane Vesicles of a Human Commensal Mediate Immune Regulation and Disease Protection. Cell Host \& Microbe. 2012 Oct 18;12(4):509-20.

28. Dasgupta S, Erturk-Hasdemir D, Ochoa-Reparaz J, Reinecker H-C, Kasper DL. Plasmacytoid Dendritic Cells Mediate Anti-inflammatory Responses to a Gut Commensal Molecule via Both Innate and Adaptive Mechanisms. Cell Host \& Microbe. 2014 Apr 9;15(4):413-23.

29. Chu H, Khosravi A, Kusumawardhani IP, Kwon AHK, Vasconcelos AC, Cunha LD, et al. Gene-microbiota interactions contribute to the pathogenesis of inflammatory bowel disease. Science. 2016 May 27;352(6289):1116-20.

30. Fitzgerald-Bocarsly P, Feng D. The role of type I interferon production by dendritic cells in host defense. Biochimie. 2007;89(6-7):843-55.

31. Srivastava S, Koch LK, Campbell DJ. IFNaR Signaling in Effector but Not Regulatory T Cells Is Required for Immune Dysregulation during Type I IFN-Dependent Inflammatory Disease. The Journal of Immunology. 2014 Sep 15;193(6):2733-42.

32. Srivastava S, Koch MA, Pepper M, Campbell DJ. Type I interferons directly inhibit regulatory T cells to allow optimal antiviral T cell responses during acute LCMV infection. Journal of Experimental Medicine. 2014 Apr 7;211(5):961-74. 
33. Martin PK, Marchiando A, Xu R, Rudensky E, Yeung F, Schuster SL, et al. Autophagy proteins suppress protective type I interferon signaling in response to the murine gut microbiota. Nat Microbiol. 2018 Oct;3(10):1131-41.

34. Giles EM, Sanders TJ, McCarthy NE, Lung J, Pathak M, MacDonald TT, et al. Regulation of human intestinal T-cell responses by type 1 interferon-STAT1 signaling is disrupted in inflammatory bowel disease. Mucosal Immunol. 2017 Jan;10(1):184-93.

35. Nikolaus S, Rutgeerts P, Fedorak R, Steinhart AH, Wild GE, Theuer D, et al. Interferon beta-1a in ulcerative colitis: a placebo controlled, randomised, dose escalating study. Gut. 2003 Sep;52(9):1286-90.

36. Musch E, Andus T, Malek M, Chrissafidou A, Schulz M. Successful treatment of steroid refractory active ulcerative colitis with natural interferon-beta--an open long-term trial. Z Gastroenterol. 2007 Dec;45(12):1235-40.

37. Atarashi K, Tanoue T, Oshima K, Suda W, Nagano $\mathrm{Y}$, Nishikawa $\mathrm{H}$, et al. $\mathrm{T}_{\text {reg }}$ induction by a rationally selected mixture of Clostridia strains from the human microbiota. Nature. 2013 Aug;500(7461):232-6.

38. Tailor P, Tamura T, Kong HJ, Kubota T, Kubota M, Borghi P, et al. The Feedback Phase of Type I Interferon Induction in Dendritic Cells Requires Interferon Regulatory Factor 8. Immunity. 2007 Aug 24;27(2):228-39.

39. Uccellini MB, García-Sastre A. ISRE-Reporter Mouse Reveals High Basal and Induced Type I IFN Responses in Inflammatory Monocytes. Cell Reports. 2018 Dec;25(10):2784-2796.e3.

40. Bordignon J, Probst CM, Mosimann ALP, Pavoni DP, Stella V, Buck GA, et al. Expression profile of interferon stimulated genes in central nervous system of mice infected with dengue virus Type-1. Virology. 2008 Aug 1;377(2):319-29.

41. Fensterl V, White CL, Yamashita M, Sen GC. Novel Characteristics of the Function and Induction of Murine p56 Family Proteins. J Virol. 2008 Nov;82(22):11045-53. 


\section{FIGURES \& FIGURE LEGENDS}

\section{Figure 1}

A

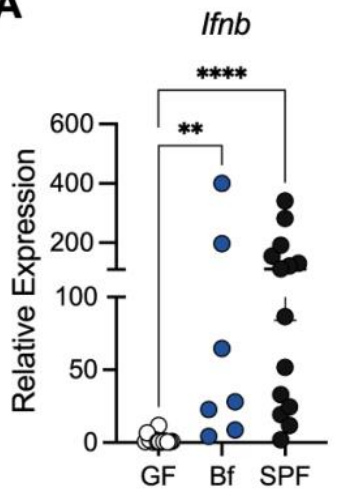

$M \times 1$

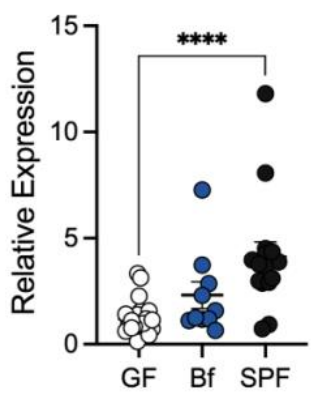

B

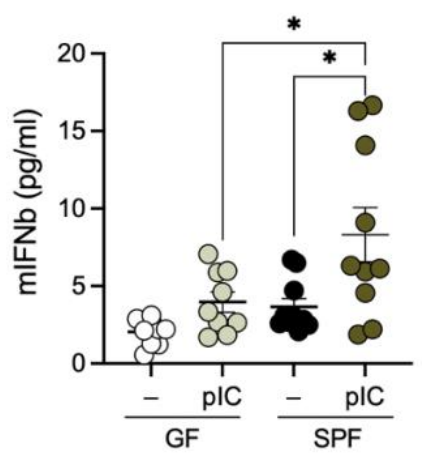

C

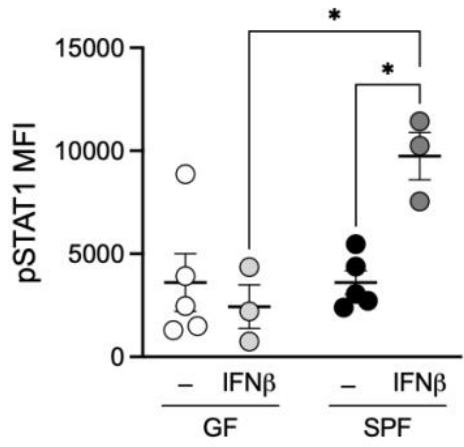

Colon $\mathrm{CD}_{11 \mathrm{c}^{+}}$cells

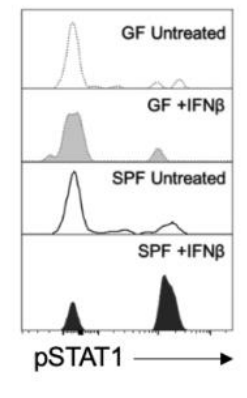

Figure 1. Commensal bacteria maintain intestinal type I IFN responses

(A) Expression of Ifnb and $M x 1$ in colon tissue from germ-free (GF), B. fragilis monocolonized (Bf), and specific pathogen-free (SPF) as measured by RT-qPCR. (B) GF and SPF colon explants were cultured with or without stimulation of poly I:C (plC; $2 \mu \mathrm{g} / \mathrm{ml})$ for 24 hours. Supernatant was then collected and measured for IFN $\beta$ secretion by ELISA. (C) Colonic lamina propria cells were isolated from GF and SPF mice and stimulated with IFN $\beta$. PSTAT1 was assessed by flow cytometry. Data are representative of at least two independent experiments. Statistical significance was determined by Kruskal-Wallis and unpaired t-test. $p<0.05\left(^{*}\right), p<0.01$ $\left.\left({ }^{* *}\right), p<0.001{ }^{* * *}\right)$, and $\left.p<0.0001{ }^{* * * *}\right)$. 


\section{Figure 2}

A

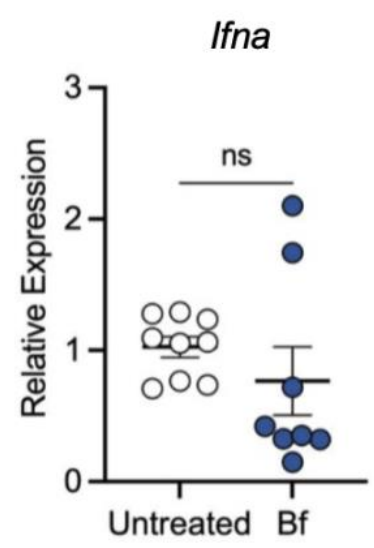

B

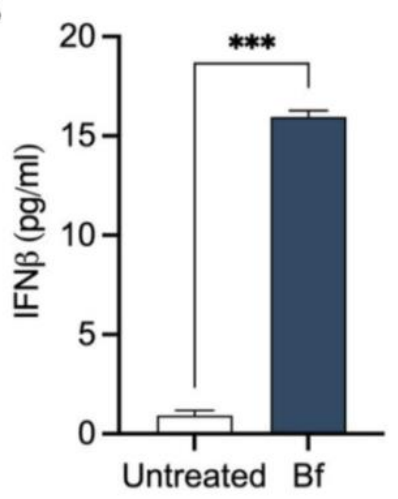

Ifnb

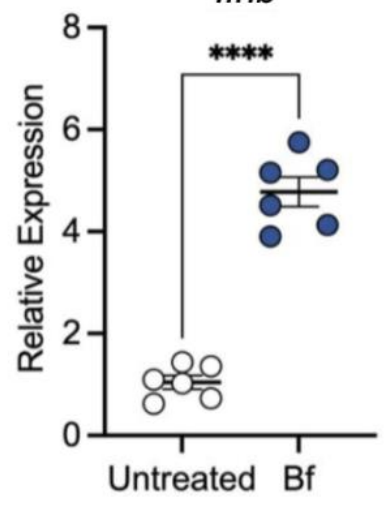

C

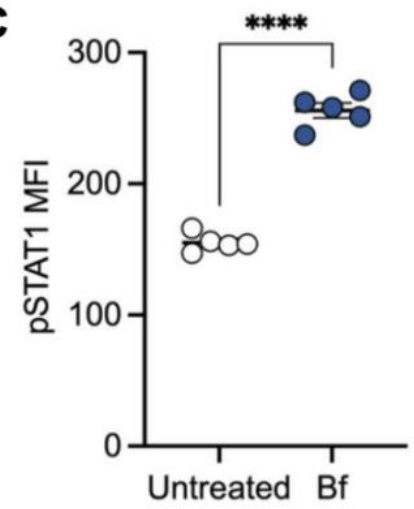

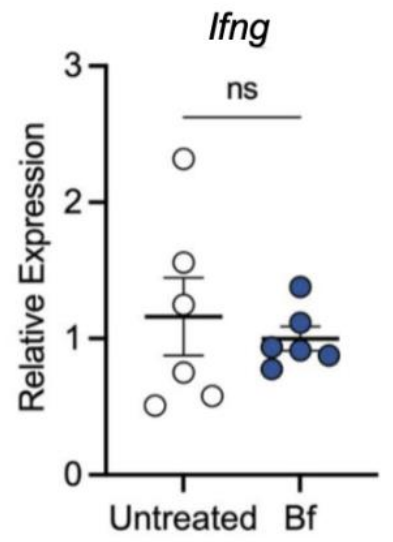

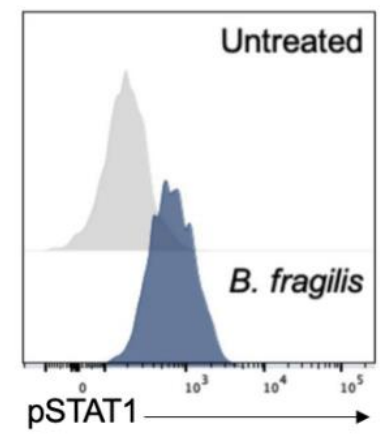

Figure 2. B. fragilis induces IFN $\beta$ expression in dendritic cells to coordinate Treg response

Bone marrow derived dendritic cells (BMDCs) were treated with $B$. fragilis for 18 hours and (A) relative expression of Ifna, Ifnb, and Ifng were measured by qRT-PCR. (B) Supernatants from BMDC cultures were collected and IFN $\beta$ secretion was measured by ELISA. (C) BMDCs from SPF mice were treated $B$. fragilis for 18 hours, and cells were stained for pSTAT1 and analyzed by flow cytometry. Statistical analysis was determined by two-way ANOVA and unpaired t-test. $\mathrm{p}<0.05\left(^{*}\right), \mathrm{p}<0.01\left(^{* *}\right), \mathrm{p}<0.001\left(^{* * *}\right)$, and $\left.\mathrm{p}<0.0001{ }^{* * *}\right)$. 


\section{Figure 3}

A

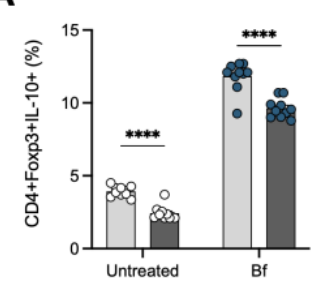

B

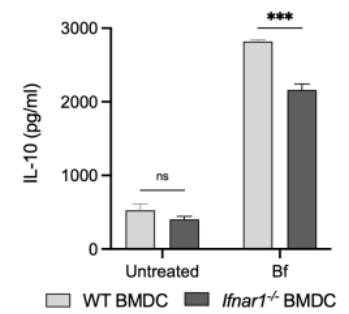

C

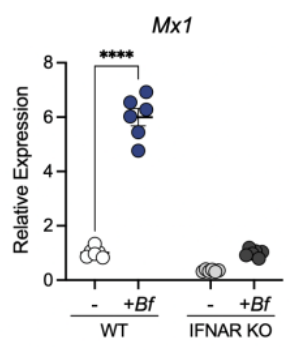

Irf3

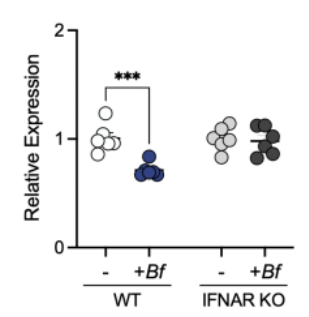

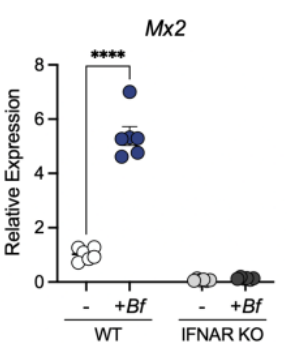

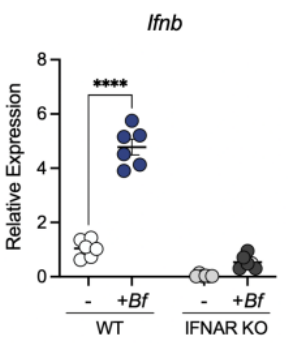

Irf7
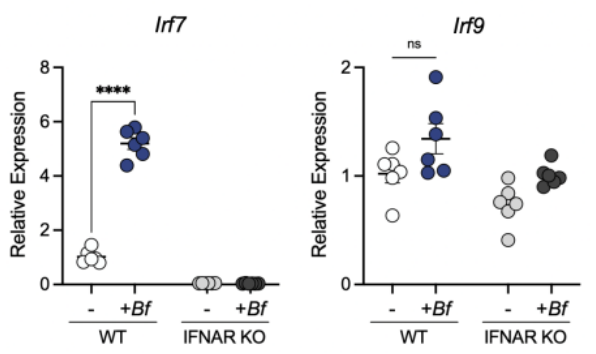

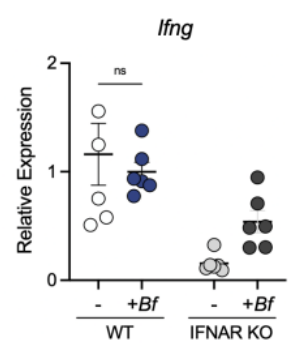

Ifit1

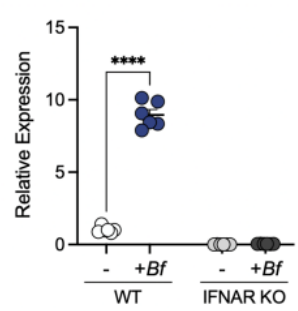

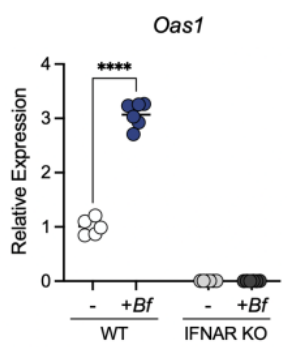

Isg15

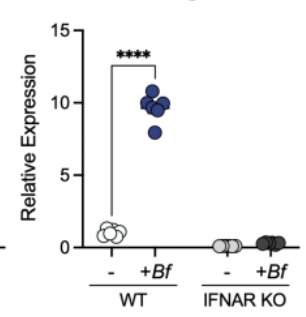

Figure 3. Type I IFN signaling in DCs are required to promote Treg responses.

WT and IFNAR-deficient BMDCs were pulsed with $B$. fragilis and co-cultured with CD4+ from IL-10 venus reporter mice for 72 hours. (A) Cells were stained and analyzed by flow cytometry for IL-10+ Foxp3+ Tregs and (B) supernatant were collected to measure IL-10 secretion by ELISA. (C) Expression of IFN related genes among untreated and $B$. fragilis-treated BMDCs were analyzed by qRT-PCR. Statistical significance was determined by two-way ANOVA. $p<0.05\left(^{*}\right), p<0.01\left(^{* *}\right), p<0.001\left(^{* * *}\right)$, and $p<0.0001\left(^{* * * *}\right)$. 


\section{Figure 4}

A

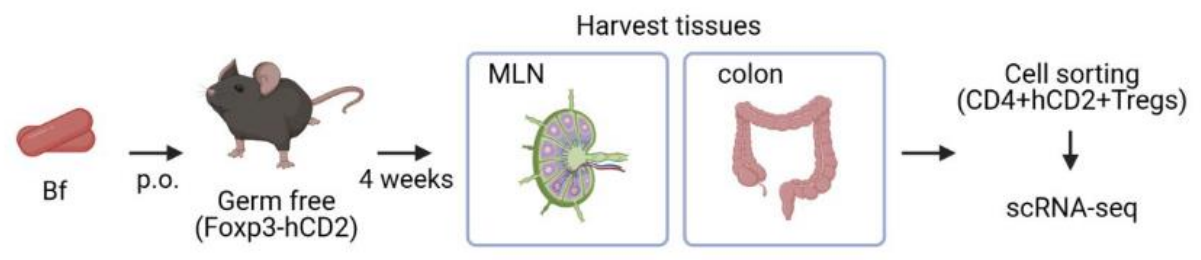

B

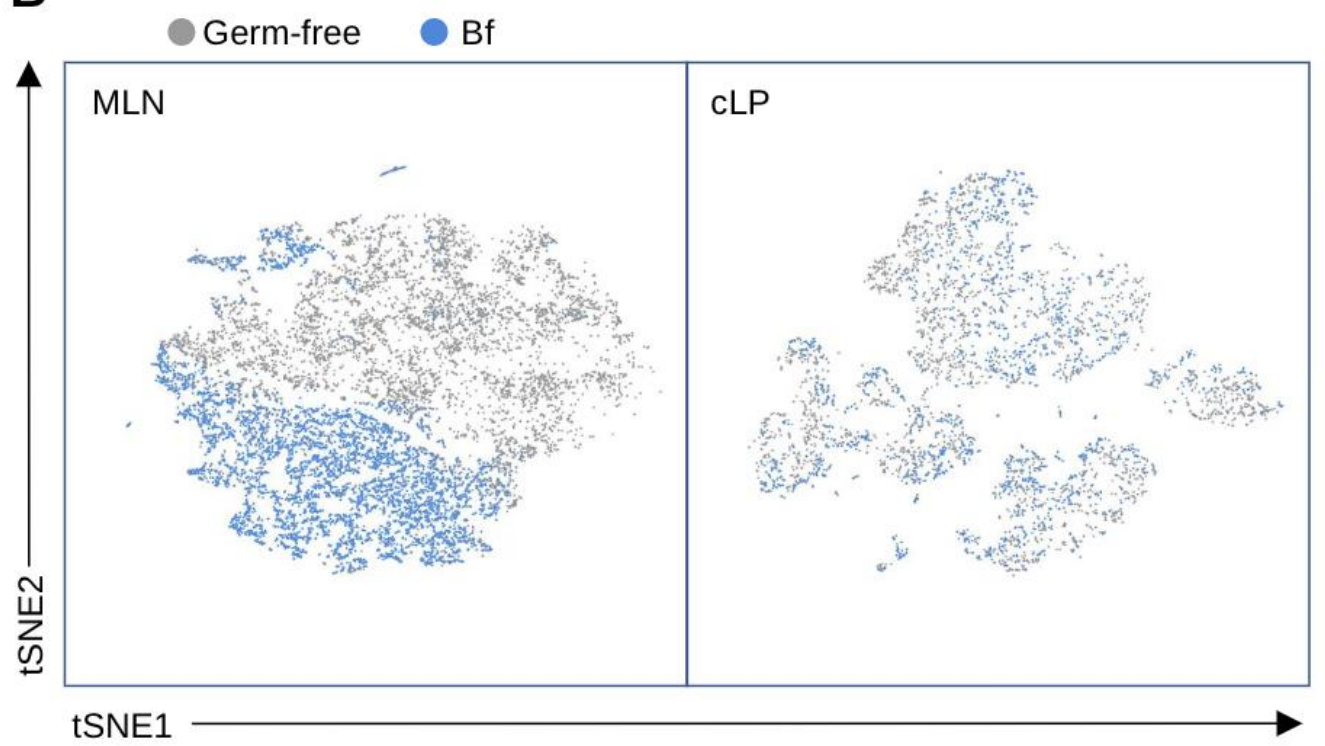

C

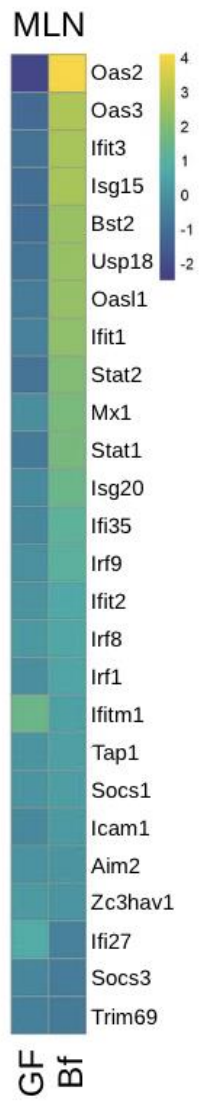

Figure 4. Bacterial colonization induces type I IFN signature in intestinal Tregs.

(A) Experimental scheme. 4- to 6-week-old female germ-free Foxp3 ${ }^{\text {hCD2}} / \mathrm{IL}-10^{\text {Venus }}$ mice were orally gavaged with a single dose of $B$. fragilis ( $10^{8} \mathrm{CFU}$ resuspended in sterile PBS). Four weeks later, mesenteric lymph nodes and colon tissues were harvested and single suspensions were prepared. CD4+hCD2+ cells were enriched and subjected to single-cell RNA sequence analysis (10X). (B) t-SNE plot of Tregs from mesenteric lymph nodes (MLN) and colonic lamina propria (cLP) using K-nearest neighbor graph-based clustering. Individual cells were colored by experimental groups. (C) Heatmap showing type I IFN signature genes from Tregs in mesenteric lymph nodes (MLN) and colonic lamina propria (cLP). Genes are colored by the difference in $\log _{2}$-fold change expression between germ-free and $B$. fragilis-mono colonized mice. 
bioRxiv preprint doi: https//doi org/10.1101/2021.1021.464743. this version posted October 21,2021. The copyright holder for this preprint (which was not certified by peer review) is the author/funder, who has granted bioRxiv a license to display the preprint in perpetuity. It is made available under aCC-BY-NC-ND 4.0 International license.

Table 1. Primers used for real-time PCR.

\begin{tabular}{|c|c|c|c|}
\hline Gene & Forward $\left(5^{\prime} \rightarrow 3^{\prime}\right)$ & Reverse $\left(5^{\prime} \rightarrow 3^{\prime}\right)$ & Reference \\
\hline Pan-Ifna & CCTGAGGAAGAGAAGAAACACAGCC & " GGCTCTCCAGAC/TTTCTGCTCTG & 38 \\
\hline Ifnb & CAGCTCCAAGAAAGGACGAAC & GGCAGTGTAACTCTTCTGCAT & Primerbank ID: $6754304 a 1$ \\
\hline Ifng & CCTTCTTCAGCAACAGCAAGGC & GACTCCTTTTCCGCTTCCTGAG & 29 \\
\hline$M \times 1$ & TGTGGACATTGCTACCACAGA & AAGGCAGTTTGGACCATCTC & 39 \\
\hline$M \times 2$ & TGGCACTTCCAGTTCCTCTCA & GGTTGTGAGCCTCTTGGCGG & This study \\
\hline Irf3 & CGGAAAGAAGTGTTGCGGTTAGC & CAGGCTGCTTTTGCCATTGGTG & 39 \\
\hline Irf7 & GCCAGGAGCAAGACCGTGTT & TGCCCCACCACTGCCTGTA & 40 \\
\hline Irf9 & TAACCGCTTGCCCTGCAACT & ACTTTGCCTGAGGCCATCCTGA & This study \\
\hline Oas1 & ATGGAGCACGGACTCAGGA & TCACACACGACATTGACGGC & 39 \\
\hline Ifit1 & CAGAAGCACACATTGAAGAA & TGTAAGTAGCCAGAGGAAGG & 41 \\
\hline Isg15 & CTGACTGTGAGAGCAAGCAGC & ACCTTTAGGTCCCAGGCCATTG & This study \\
\hline
\end{tabular}

